\title{
Sustaining the unsustainable: Wearable technologies as informing running-practice in urban schools
}

Nikki Rotas nikki.rotas@mail.utoronto.ca

Ontario Institute for Studies in Education, University of Toronto.

\section{Abstract}

Using wearable technologies in educational research and in relation to group-running, this paper inquires into new methodological landscapes through posthumanist and new materialist theories and methodologies. Embedding practice in an urban school in Canada, this paper particularly engages with the material and materiality of environments as a way to flesh out a methodology that attends to the complexity of technologically-mediated bodies in movement. This understanding suggests that technologies matter in ways that are generative of the 'realities' in cities, communities, and what is learned in schools. Concluding with a questioning of data and what might become of it, I suggest that a re-valuation of data, method, and methodology - as that which is part of a continuum - might redraw new cartographies in educational research.

Key-words: Ecology, Movement, Running, Urban Schools, Wearable Technologies

Beyond pleasure and pain, life is a process of becoming, of stretching the boundaries of endurance.

(Braidotti, 2013)

\section{Introduction}

In Lost Subjects, Contested Objects, psychoanalyst, Deborah Britzman (1998) writes of the possibility of "unlearning" traditional practices and ways of knowing. She insists that to learn is to unlearn through uneasiness and discomfort. A decade or so later Elizabeth Grosz's (2011) Bergsonianinspired ontology provokes her audience with possibilities of "undoing" and "unraveling" the Self. Grosz describes the "undoing" process as a self-differentiating movement that is created within and/or in-between humans, nonhumans, things, and/or systems. It is this process of unlearning and undoing, becoming uneasy and understanding in ways that are not-yet-known that has become of inquiry in posthumanist and new materialist research. Although posthumanist and new materialist theories and methodologies are not embedded in psychoanalytical practices or poststructuralist frameworks, the influence of the 'posts' can be traced to the material feminists of the 1990s, such as 
Grosz. Moreover, psychoanalytical roots of practice are exposed in the works of Deleuze and Guattari, which are often used in relation to posthumanist thought and new materialist methodologies in educational research (Braidotti, 2013; Braidotti, 2002; Hultman and Lenz Taguchi, 2010; Mazzei, 2010; St. Pierre, 2013). It is particularly Deleuze and Guattari's (1977) collaboration, Anti-Oedipus, that theoretically exhumes the psychoanalytical through a rhizomatic inquiry of familial relations. It is, however, Guattari's (2013) solo work that touches on the psychoanalytical as a way to reconceive of practice (i.e., methods and methodologies), perhaps more directly than in other works and with Deleuze. It is thus not the task of this paper to dismiss genealogy or traces of other disciplines and of the past. For is it not the psychoanalytical field that has had a hand in teaching the 'human' that an understanding of the Self is an impossibility (Snaza et al., 2014)? Perhaps Britzman's brand of psychoanalysis said it best when she stated: "If a pedagogical project is to move beyond the repetition of identity and the only two subject positions allowed when identity is understood as one of self versus others, then pedagogy itself must become a problem of reading practices, of social relations, and of the means to refuse to think straight" (1998, p. 92). Refusing linearity, this paper decentres the Self through what Braidotti (2013) calls "micro-practices," or what I will refer to as 'ecological practices.' Such practices collectively redefine relations with embodied others, with science, technology, space, and place. Braidotti particularly argues that technology has become "our new 'milieu,"' suggesting that the intimate and complex relations generated in and of these milieus exceed the prosthetic-mechanic understanding that modernity had conceived of it ( $\mathrm{p}$. 83). Interest in exceeding past-present-future understandings then suggests that how we come to learn and with technology in schools "matters" (Barad, 2007) in different ways. Pedagogical practice as ecological entails a methodological reconsideration of how knowledge is produced with technologically-mediated bodies in "more-than-human" environments (Manning \& Massumi, 2014).

As part of a larger research study that inquires into the relational process of school gardening and ecological "intra-activity" (Barad, 2007) within urban landscapes, this paper focuses on grouprunning as an ecological practice that sets in motion new cartographies to be drawn in methodological research. Using wearable technologies as a method, or what I will call a "technique" (Manning, 2013a) that captures data, I will argue that wearable technologies also attend to the complexity of technologically-mediated environments in movement. The latter suggests that wearable technologies (such as the mini HD camera worn in the study) are implicated in a generative movement that works to compose and re-compose human, animal, and thing bodies in an ecology that expresses "technicity" (i.e., a qualitative change) (Manning, 2013a). This proposal suggests that ecologies operate in ways that absorb territorially bounded relations, but also entertain becoming movements that are in emergent relation with environments as they form.

I embed this work within an urban landscape in order to address the material and materiality of cities, urban communities and schools, and also to argue that technologically-mediated bodies could never be fully captured or known (as data) by the technological apparatus. In the first section of the paper, I turn to Deleuze|Guattarian philosophy in relation to educational research to write of a becoming process that involves the simultaneous enactment of theory-practice. To develop this argument, I use the practice of running, not as a method, but rather as a technique to explore new relationships between wearable technologies and the body. I briefly touch on technology and its negative portrayal in popular culture and educational discourse in order to point out that just within 
the last 5-10 years, technologies have come to mediate bodies differently and thus matter in different ways. The latter also touches on the inhuman(e)ities of technology as well as suggests that nonhuman bodies and material objects matter in processes of learning. In the second section of the paper, I present running as a collective movement that is enacted by a group of elementary students - wearing technology - in an urban school and in the larger community. I describe our use of wearable technologies as a technique that captures, or records partial movements (as data). I then describe the entanglement of the body, wearable technologies, and the larger environment as expressing technicity, which involves the production of a qualitative change. This understanding suggests that wearable technologies compose with urban environments, as well as suggests that the practice of running has the potential to "activate" (Manning, 2013a) different relationships to place. In the latter section of the paper, I introduce topological thinking in relation to our running-practice as a way to think qualitative research as that which cannot be measured. I problematize the notion of measuring data through an intimate exploration of relationships in urban schools and communities, which signals towards the impossibility of capturing 'truth.' Through Braidotti's (2013) notion of "nature-culture" and that which is part of a "continuum," I conclude the paper by offering one of many ways qualitative researchers can continue to rethink methodology and what data might become.

\section{Bodies and Technologies}

In social science research the running body has been theorized in relation to many fields of study, including physical education (Larsson \& Quennerstedt, 2012) and media and gender studies (Renold \& Ivinson, 2013). In curriculum research, running has been explored as a pedagogical practice through co-constructed running-body narratives, which served to document the relational process of research (Sanders-Bustle \& Oliver, 2001). More recently, running-body narratives have been explored poetically and as a method of becoming that alters subjectivity (Rotas, 2012). The running body, however, has not been theorized in relation to audio-visual technologies and in particular wearable technologies, such as the HD camera worn in the study. A great deal of research has been produced on the relationship between technology and the body (Braidotti, 2013, 2002; Hayles, 2012; Weaver, 2010). Particularly in feminist research, Haraway's (1991) work has certainly altered academic landscapes in ways that question, not only the capacity of technologies but the companionship of nonhuman species (see Haraway, 2008). Influenced by Haraway, Rosi Braidotti (2013) in her recent book, The Posthuman, has activated notions of subjectivity through a "conceptual creativity" that moves beyond an analytic posthumanism; it moves toward the creation of "affirmative" concepts and practices that re-think human-animal-technological-geographic relations. In environmental education discourse and in schools, on the other hand, negativity is often expressed towards technology. The 'putting-down' of handheld devices and the return to what is 'natural' often plays out in schools. Access to technologies in terms of desktop and/or laptop computers (for each student) is not always a reality in public education. However, when investments are made in technologies, such as the purchasing of a classroom-set of android tablets (which was the case at this particular school), teachers were either unsure how to use the tablets in relation to the curriculum, and other teachers felt that it was just too complicated and time-consuming. 
Negativity towards technology can be traced to the cinematic imagery of the 1950s and more recently to the advent of new technologies, such as the World Wide Web. The invention of the Web twenty-five years ago has generated and continues to generate alarmist concerns about access to information and security. For instance, remember the Y2K bug or the Millennium Bug? This event sparked a technological crisis, which was based on predictions that the Internet and digital data would explode as a result of the change in millennium. Panic ensued which prompted international businesses and governments to backup their data as well as upgrade their technological systems at a rapid rate. I note this particular moment in history in order to point out that technological innovation is often reduced to fear-inducing scenarios, which could similarly be said for how sustainability issues are framed in popular culture. The cinematic imagery of disaster, for example, follows a predictable alien-monster-other-technologically-driven sequence that produces death and disaster (Braidotti, 2002). These popular images further serve to generate vulnerability between humans, technology, and the environment. Braidotti argues that posthumanist theories rather take an affirmative turn, stressing the intimacies generated between embodied subjects and technologies on local and global scales. This, however, does not mean that the histories of disaster and oppression of people are not to be remembered because they are too negative or too "inhuman(e)" (Braidotti, 2013). Intimacy does not promise satisfaction or joy; indeed, it has the potential to harm and to produce violence. Just within the last ten years there have been ecological disasters of massive scale, including earthquakes, tsunamis, and nuclear disasters that have been covered by the international media and experienced by communities world-wide - communities that continue to experience the history of all three events. My neighbours, upon their recent return from Japan, reminded me that it has been three years since a tsunami hit the Japanese northern coast, causing radioactive poisons to spill into oceans and destroy habitats and communities. The history of this event will not only be relived differently through travel, technologically-mediated memory, written text, and visual images, but its history is very much present in the habitats and communities that have been destroyed. This devastation is also part of the earth's futurity, as radioactive materials continue to poison, displace, and decompose bodies. The histories of people, place, and technologies; the use of people as objects; the colonizing practices that claim place; and the technologies that destroy it must not be erased. The inhuman(e) histories of the past, present, and future cannot be erased by posthumanist theory. The practice of becoming not posthuman, but rather becoming different is a process of self-organization and of redefining one's relations with territorial space (i.e, urban, social, ecological and so on) (Braidotti, 2013). Becoming, argues Braidotti, "expresses multiple ecologies of belonging, while it enacts the transformation of one's sensorial and perceptual co-ordinates, in order to acknowledge the collective nature and out-ward-bound direction of what we still call the self" (p. 193). Thinking (posthumanist) theory-practice might just be one of many ways qualitative researchers can begin to reconceive of becoming, not only as a theoretical tool, but a possibility in schools.

\section{Becoming in Curriculum Research}

In curriculum research, the "rhizome" has been taken up in many different ways (see de Freitas, 2014, 2012; Mazzei \& McCoy, 2010; Phillips \& Larson, 2012). The rhizome is the 'first' plateau in Deleuze and Guttari's (1987) collaboration - that is, if the reader chooses to read their book from front-to-back. It is also the plateau in which the orchid-wasp relation is laid out, and it is often the entry-point or perhaps, more fittingly, the first "encounter" - in the Deleuze|Guattarian sense of the 
word - that the reader has with their philosophies. Upon reading the first plateau, it may seem that the orchid and the wasp is that of a simple relation, a method based on mutual need and necessity - a reproductive goal. The flower, for instance, is pollinated and the wasp is fed and satisfied - prepped for its future journey. There is a mapping process at work here that Deleuze and Guattari describe as a (co-composing) movement that enacts becoming. This enables a thinking of method differently.

Mazzei and McCoy (2010), for example, rethink method and data in ways that "think with Deleuze." Resisting Deleuze|Guattarian concepts (like the rhizome) as metaphor, they attend to data as generative of unthought questions and ways of knowing. The rhizome as metaphor will thus not work to produce new knowledge. What seems far more productive is asking how might the classroom operate rhizomatically and on its own terms (see Springgay \& Rotas, 2014)?

Although Deleuze and Guattari do not layout any sort of 'method' and/or 'methodology,' their work invites a commitment to movement as "veritable becomings" as well as commits to a questioning that attends to how movement territorializes place. As noted through Braidotti's work above, it is not enough to just move, or to write of becoming. Change must be enacted thorough a processorientated practice that undoes and asks: How does this work? And what does it do? In thinking theory-practice, then a serious consideration and questioning of procedures and practices is significant. The challenge of new materialist methodologies and what this paper struggles with is the not-knowing of how until its actualization; and even then one cannot 'fully' know someone and/or something. Acknowledging that we (researcher, teacher, and students) could never know what is 'truth,' we engaged in an experimental running-practice not knowing what we would learn. Not knowing what change or "encounters" potentially unfold, we attached wearable cameras to our running-bodies. As a technique, the wearable cameras partially captured our running movements as data/form. However, rigorously attending to how our running-group "intra-acted" (Barad, 2007) with place, the wearable cameras became implicated in the shaping and re-shaping of relationships. The latter suggests that "in-act" (Manning, 2013a) of running, the group has the capacity to express a collective movement that undoes place and traditional conceptions of what data 'is.'

\section{"Embodied and Embedded" Running-Ecologies}

Composed of 10-15 students and 3-4 teachers, the group ran together afterschool and twice a week for one hour and fifteen minutes. Participation was voluntary and varied throughout the weeks, depending on student commitments at school and/or home. We ran different routes every week within the urban community in which the school is embedded. Attached to our running bodies were miniature HD cameras, which are marketed towards and primarily used for extreme adventure or action photography and video. Commercially marketed as the GoPro, the camera has the capacity to take high-definition photos and video while it is in movement. The camera can be attached to human and nonhuman bodies using adjustable straps. With the use of plastic mounts, the camera can also be attached to moving objects, such as motorcycles and cars. Its technical capacity includes functions such as Time-Lapse, which captures a series of photos over second intervals. Photos can be captured every $0.5,1,2,5,10,30$, or 60 seconds. Photo-burst is another function that captures multiple photos in short intervals of time. For instance, 3,5 , and 10 photos can be captured per second, or 10 photos per 2 seconds, depending on the camera's edition. The Hero 3+ Silver edition camera was worn in the study by the researcher, teacher, and students (Grade 2/3, ages 7-9). We wore the cameras on 
our head, chest, upper back, and wrist, and used the video recording function, which was set (by default) at a resolution of 960p and 30fps (frames per second). This created an ultra-wide field of view. At times we wore multiple cameras and recorded during schools hours and afterschool activities.

There was an initial newness to wearing technology and the students expressed their desire to wear the camera at least once during running-practice. The novelty of wearing technology, however, quickly wore off. The camera became another "thing" in our practice as new things grasped the students' attention (Bennett, 2010). My intentions to wear the camera throughout the entire schoolday and afterschool accustomed students to the cameras' everyday thingness. Initially students knew it was there. They often peered into the camera lens, some keeping their distance and others curiously asking questions, such as: What is that? What is it doing? Is it recording? Upon answering these questions, the questions eventually subsided. Students also stopped looking aporetically into the camera lens. When students wore the camera for the first time, some were unsure and felt uneasy; others performed for the camera. For instance, when students wore the camera they often took on a leadership role by directing interaction, or suggesting running-routes to take. However, during our runs and as the running intensified, students forgot that the camera was there and so, they stopped directing others. Runners were swept up in the running movement and the mobile camera recorded their interactions. Intimate conversations that I did not see, nor would never hear due to my role as a teacher and an adult in the school were also recorded. The wearing of technology thus enabled a recording of relations as they unfolded. Furthermore, the camera recorded our pounding movements as they met the paved sidewalk and street. Notably, the exhaustion of our breath as it related to the environment served to remind us, along with the visual image, that we are "embodied and embedded" humans (Braidotti, 2013). Yet there was a more-thanhuman quality of experience that was inarticulable and in-act of our running. With and in our breath there was a rhythm that expressed a quality beyond physicality and exhaustion. The wearable camera, unable to capture this inaudible beat, also reminded us that the technological apparatus was, too, generative of the force of relations that shaped the running-ecology as it formed.

\section{Difference, Technique, and Technicity}

Manning (2013b) suggests that one technique in the study of philosophy is a close reading of a text. A technique in the practice of running is pacing oneself. And when a child first learns to read, a technique that is often used is the scanning of visual images in order to help the reader guess at words and to understand the text. The repetition of technique is thus necessary when learning to do something for the first time. Schools to a certain extent require techniques, routines, and linear models of time to operate with. Techniques are, however, not non-negotiable practices; they create what Manning (2013a) calls "landings sites," which give students something to work with. Teachers would perhaps call this 'scaffolding.' It could involve non-didactic modeling to a certain extent, or activating a "mode of engagement" (Manning, 2013a). Technicity, on the other hand, involves emergence; it attends to the networks, forces, and flows that produce qualitative changes in and of cities, schools, and community-spaces. Many of Deleuze and Guattari's concepts think about relations as emergent and alive in the moments of encounter. The "event," as another Deleuze|Guattarian concept, describes a non-evaluative engagement with place and others as "singularities" in a 
problematic field of relations. They further describe the event as an ethical and political engagement due to its ontology of non-relation, which absorbs the social, cultural, and technological, and recreates them as singularities and/or through this process of "individuation" (see Simondon, 1995). Singularities are not fixed points, nor identities; they are qualities of experience that inform the relational field as it intimately organizes itself out of chaos, cracks, and this "difference" that Deleuze and Guattari write about. Difference, from this perspective is a qualitative change and thus, a movement that moves the field of relations from what it used to be. This does not require a geographic re-location per se; it potentializes a qualitative change that is emergent to its relations with others and place. Technicity, therefore, is an affective field of rhythm that informs ecologies in the process of formation, and that which produces difference. In relation to reading and running, for example, technicity would entail the unfolding of these processes in unique ways for each student. The reading|running process would also unfold differently each time for that particular student. Technicity is not repetition, however, habit can take form only when durational force (i.e., networks and flows in and of experience) is unattended to for reasons that tie the subject to economic models of productivity and consumption (Manning, 2013a). The capitalist subject thus becomes programmed to stick to patterns or paths that make cities, communities, and schools function in predictable ways.

Deleuze and Guattari produce an extensive vocabulary that is helpful in thinking about unpredictability, complexity, and emergence as possibilities in urban landscapes. According to Rajchman (1998), Deleuze and Guattari's philosophy is that of the city; a spatial philosophy that is interested in the networks and flows that compose, decompose, and re-compose landscapes. In and of chaos, Deleuze and Guattari argue that the city-as-assemblage and/or ecology organizes itself. It is perhaps statements like the latter that prompt urban planners to refrain from using Deleuze and Guattari's work as a methodological tool kit to plan city-spaces. However, their theories and particularly their notion of "emergence" has been given serious consideration in architectural discourse (Eisenman, 1999; Gins \& Arakawa, 2002); city planning and software programming (Johnson, 2002); as well as swarm intelligence systems in relation to social and cultural conditions (al-Rifaie, Bishop \& Caines, 2012; Vehlken, 2013). Their work is often shrugged off by the disciplines as impractical, too abstract! It seems to me that thinking theory-practice was something Deleuze and Guattari were doing all along. Indeed, Deleuze and Guattari's concepts are risky, but not impractical and certainly not meant to be applied. I view their concepts of the "rhizome" and the "diagrammatic" as mapping tools that operate with environments and in doing so, create new cartographies through the process of mapping. Although Deleuze and Guattari do not call their concepts methods, nor would stake claim in the development of a methodology, I suggest that their concepts materially exist as landing sites and for the purpose to see what they (i.e., concepts) could do. For them and for Foucault, theory was never created for the purpose of application. They state: "The relationship which holds in the application of a theory is never one of resemblance...Practice is a set of relays from one theoretical path to another, and theory is a relay from one practice to another" (Deleuze \& Foucault, 1977). A posthumanist pedagogy, which involves a thinking of theory-practice, is thus not to be applied nor offers best practices for teaching. Suggesting what should be done would in turn imply that practices already exist for the purpose of mastery and repetition. Such practice often does happen in schools through the relentless photocopying of existing templates and the repetition of lesson plans throughout the years, even decades! Educators need techniques to activate modes of 
engagement, not to replicate them. To activate practice suggests a mode of engagement that is not mechanical. The process of doing something, whatever it is, would operate its own making with the urban-technological-animal-viral-vegetable environments (Braidotti, 2013). To put this in another way, the learning process and its risk will determine how movement moves and what it will $d o$.

\section{Movement: Running-with Metal}

Our learning process was running. We all moved differently, some faster, some slower. We even walked at times which provoked the students to create a different group they called the "Fun to Walk Club," and which experimented with slow to speed-walking movements. The running-group lived in the community in which we ran. The runners enjoyed pointing out their homes and that of their friends as we ran by. Students even knew the name of the local ice cream vendor; his truck moved with us on our bi-weekly routes. We ran on sidewalks lined by housing units and tall apartment buildings. "Zigzagging" (Braidott, 2013) through the streets, we often reached the train tracks and ran alongside the trains - its metal movements ran through our running-bodies. It seems that the ruderal ecologies of the urban landscape ran with us, too. The rapid spring-time growth of roots and shoots followed us along the tracks. The protruding growth of ruderal species inhabited the smooth and jagged cracks on sidewalks and in buildings. Students often pointed out the unruly growth patterns and unusual locations of ruderal plants, noting the endlessness and pleasantness of what they coded as "pretty flowers." Also referred to as "wildscapes," ruderal ecologies spontaneously colonize urban sites and are seen as a threat to nature (Gobster, 2012). The developing field of urban ecology (see Jorgensen \& Keenan, 2012), however, offers ways of thinking about urban environments as living landscapes that respond to changing environmental conditions, opposed to thinking about these places as abject, or places one would be hesitant to call home (Gobster, 2012). Using a similar approach, Jane Bennett writes of environments as alive. She makes note of things as having thingness, or to put it in her words, "vitality" and thus the power to affect and effect place. Specifically, she notes the power of metal, or "metallic vitality" and its capacity to transform itself in many different ways. Through Manuel De Landa's (1995) work on the dynamics of "spreading cracks," she suggests that cracks (such as those on sidewalks and old buildings) are operative of defects. She argues that "the line of travel of these cracks is not deterministic but expressive of an emergent causality, whereby grains respond on the spot and in real time to the idiosyncratic movements of their neighbors" (p. 59). Bennett expresses a relational dynamism of things, which entails an ontology attentive to localized relations. This also requires a "differential measure" of movement and time, which will be discussed below through the work of mathematician Bernhard Riemann.

Writing about mathematics in educational settings, de Freitas (2014) presents Riemann's theory of "manifolds," which perhaps more accurately is described as a topology that is open to emergent relations in localized environments. Riemann's research and particularly his invention in differential geometry is important to mention for its emphasis on the intimacy and fluidity of place. His work transformed the ways geometric objects are viewed, by shifting the focus from traditional scientific analysis to a qualitative study of surfaces, relationships, as well as curvature, which enabled a differential measure (de Freitas, 2014). For Riemann, what became of study was not form, but rather the non-metric relationships and connectedness between figures and the points of a figure (Hilbert \& 
Cohn Vossen in de Freitas, 2014). The surface of, for instance, a polyhedron became the study of a surface open to variation and to contradictory and multiple geometries (de Freitas, 2014). This shift in geometry as topology tested the limits of empiricism, working at an ontological threshold that does not impose judgment or analysis from the outside (i.e., external environments) (de Freitas, 2014). It is particularly the differential measure of curvature that I suggest offers a qualitative understanding of how movement moves and how the running-group moved as a topological surface.

de Freitas describes the curvature of a surface as that which is characterized by different speeds of movement, suggesting that speed may differ from point-to-point on the surface of a figure. This not only suggests that movement moves at different speeds, but also attends to an ontology that is localized and immanent to say, the polyhedron, or to the running-group. This further suggests that the polyhedron and/or the running-group becomes a space in itself (de Freitas, 2104). As movement, the figure and/or group does not follow a linear path. Its curvature and what Manning (2013a) calls its "pulse," is also the pushing of its limit. Drawing on the work of choreographer, William Forsythe and his techniques of activating dance, Manning and Massumi (2014) explain that linearity collapses into intervals of movement. At the limit, the body looses "its functional capacity to chain positions and posture meaningfully and adaptively. It has no choice but to surrender itself to its own order of sensation" (p. 40). And similarly, Riemann proposes that between the points on its surface is where the figure has the capacity to order itself. However, Manning and Massumi remind us that movement never stops, as it folds back into itself and unfolds, relating to the larger non-localized field in which it returns (potentially different). It is rather the act of pushing beyond the point of the figure where the limitations of mathematical practice can be undone. This can produce a qualitative change that not only redraws cartographies relating to geometry, but potentializes the entanglement of disciplines outside of its mathematical field.

Topological thinking in relation to mathematics offers a malleable quality to think theory-practice in ways that undo common(sense). However, Riemann's mathematical theories dismiss the embeddedness of relations and the linearity of time. For instance, Riemann's differential measure of curvature risks dismissing the polyhedron as a material object in math and science that is then used - through human-centred frameworks - to constitute and shape math lessons in schools.

Furthermore, conceptualizing the running-group as a space in itself ignores what is outside of it. Ignoring the outside is thus a choice to erase the power of other ecologies to affect and effect the running-group. What Forsythe's techniques of activation tell qualitative researchers is that "in every movement's rise and fall, at any-point there is an imperceptible interval where the rising and falling coincide" (Manning and Massumi, 2014, p. 40). What this now suggests is that inside-outside and affect-effect are simultaneous productions of what becomes 'reality.' The interval is the point of departure at which, Manning and Massumi explain, the "body subside[s] into its movement pulsing, which will then throw itself a curve" (2014, p. 41). This is no longer a matter of points on a figure. Movement is matter and it undoes form through its intensification of environments. As the runninggroup absorbed (among many things) the metal movements of the train, an improvisational movement between the inside-outside generated new modalities of running that did not follow linear paths, but rather followed intensive routes that shaped experience and thus, determined its own urban curve. 
Interested in undoing theoretical representation, Braidotti writes of zigzagging as a processorientated practice of becoming that shapes subjectivity. She insists that the practice shapes its own curve "in-between nature/technology; male/female; black/white; local/global; present/past - in the spaces that flow and connect the binaries" (p. 164). This non-linear movement expresses a Spinozian notion of "enthusiasm" that Manning (2013a) explains captures the unformed qualities of experience in-between movement. Risking what might seem like the application of theory or implementation of a method, the running-group actually performed zigzagging movements. Initially they were enthused (i.e., literally excited) by the garbage and recycling bins that became obstacles on the sidewalk every week on garbage pick-up day. However, enthusiasm as movement does not take form and certainly cannot be reduced to a zigzag pattern. Zigzagging was not formed as a method to avoid the garbage bins, but rather the bins activated a new technique in the process of our practice. Put differently, the running-group literally zigzagged through the streets, but it is not this literal movement, in its representational form, where relations to technology, the self, and place become undone. Nor does zigzagging represent a running method, nor was the movement triggered by a conceptual framework or application of theory (Braidotti, 2013). Zigzagging was invented in and of the process of running, in and of humans-animals-objects-things. Therefore, what became in and of our zigzagging movement was not the expression of enthusiasm as delight. What became was enthusiasm as a qualitative difference that was emergent to the relations with the temporality of place. Zigzagging as enthusiasm outruns the pattern; and the bins become a positive force, or what Manning \& Massumi call an "enabling constraint," that creates new movement, rather than impedes it. Enthusiasm cannot be captured nor measured; its difference is felt in the pulsating rhythms that inform the running ecology as a collectivity, not a pre-formed 'group'. As a collectivity (i.e., intensities of composition) and not as a running-group formed by others from the outside, the collectivity expressed an uncapturable, self-organizing enthusiasm through the co-composing movements of runners, technologies, garbage bins, sidewalks, train tracks, ice cream truck, and ruderal cracks. And perhaps it was this enthusiasm that escaped the running-ecology and that forced to form the "Fun to Walk Club." The Club became a new node in the research process that continued with an experimental practice, but through a different mode of engagement and degree of intimacy.

\section{Urban Intimacies}

William James (2003) reminds us that "relations are of different degrees of intimacy" (p 24). Words like with and in-between (as mentioned above); and words like near and towards are conjunctive terms that express a relation of connection (James, 2003). 'Other' words, such as inclusiveness and multiculturalism have been and are often used in urban schools as a way to connect and to intentionally include Others. Inclusiveness often plays out through school board-wide identified character development traits, such as kindness and caring, empathy, and fairness to name a few. Every month, students who express these characteristics are rewarded with a paper award and a shiny pencil for their 'inclusive' behavior. Multiculturalism, another term, was popular in the educational discourse of the early $80 \mathrm{~s}$ as well as, at that time, a key term in Toronto's mantra for an all-welcoming city. Just like inclusiveness, the term multiculturalism plays out superficially through a once-a-year potluck event at which teachers and parents from the community bring one 'ethnic' meal to share with Others. The potluck occurred towards the end of the school year at this particular school, which I argue signals towards the superficiality of the event. The potluck as an event is 
different from the "event" that I previously described through Deleuze|Guattarian terms. Rather, potluck events can work to mask "molar striations" (Deleuze \& Guattari, 1987), which involves the orchestration of unethical relations that consume the Other. Braidotti insists that offering a critique of power relations and/or of the potluck event is not enough. If school events are going to continue fostering practices that knowingly or claim to unknowingly territorialize place, then these events must be punctured in ways that creatively poke holes, knot, and twist the fabric. Doing so could potentialize "events" and ways of being together differently - not unified (as a whole) - in schools.

Urban schools are often identified as 'inner-city' and in turn are mythologized through discourses of fear, danger, and helplessness. The inner-city school and surrounding community is often seen as in need of 'tidying-up,' and students are often spoken about in terms of needing intense behavioural management (see McCready and Soloway, 2010). Opportunities for outdoor exploration and experimentation are immediately shut down by justifications that students cannot explore the school grounds, or larger community due to the risk of things, such as needles and condoms that have been of issue at the school in the past. This latter example indicates that movement (of bodies) is constrained and controlled. Deterring exploration through fear, further indicates the shuttingdown of intensities that are productive of new relations to place. In using the term 'urban,' this work resists more of the sameness that terms, such as inclusiveness and multiculturalism materialized. Tuck (2013) argues that a re-articulation of what 'is' urban is necessary. She has been working to disrupt the term by referring to 'urban' as a nexus of material and experiential realities. In attending to the embodied and embedded realities of place, techniques of relations, such as our runningpractice will not reproduce definitions of what urban 'is,' but rather activate new experiences in and of the urban landscape. This does not mean that urban schools and communities will become socially just places. What practice as process does, is potentially activate the materialities of place. Such practice also responds to lived experience as that which cannot be coded for data analysis, nor retold from the outside.

As a technique of relation, running-practice was not meant to train students for anything in particular. The group formed as an open-ended process capable of activating "event" potential. It served as an opportunity for "creative participation," (Manning \& Massumi, 2014) which entails a self-organizing potential in the act of, in our case, running with technology and with and in the urban community. In and of this technological milieu that cities, communities, and schools can force to form (in their own terms), the activation of practice must at least be considered as potentially productive of new relationships to place. Not based on traditional participatory models, this proposes a revaluation of participation as that of "intra-action," which à la Barad insists that matter matters because it moves. Our running movement not only mattered because it composed with the garbage bins and ruderal plants. Our running movements mattered because it created new events, such as the "Walk Club" instead of more of the same (i.e., the potluck). Through the 'eventing' of running, which is that of contingency and constant change, the runners twisted what is usually expected in schools and communities, and further poked holes in the school fabric by inventing a new walking practice that had one parent asking: "What is the purpose of this?" I did not have a "general response" (Guattari, 2013) for this parent, but it is this very question that often leads to predictable practices that reproduce the same lesson plans and templates. However, the question is a legitimate one in the current educational climate of standardization in which curriculum documents demand 
that educators teach with an intended purpose. That being said, I still do not have a general response, or a tidy definition as to how the process of running and walking can (potentially) change what is experienced as 'urban' in other environments. Our practice of running is not to be replicated and our walking-practice was not intended prior to our engagement with and in the community. If qualitative researchers and teachers must manage and work with the language of standardization, then the "purpose," or goal of using wearable technologies in practices of group-running and walking was to enact a qualitative change that rethinks the materialization of bodies as a co-composing production of reality. If such thinking can be thought, Barad (2007) explains that this implies "that material constraints and exclusions and the material dimension of regulatory practices are important to the process of materialization, that performativity must be understood as not simply an issue of how discourse comes to matter but also of how matter comes to matter" (p. 207). Process as practice will thus inform future ecologies that qualitative researchers cannot know beforehand, nor ever fully know. This is a contingent practice that similarly to the field of urban ecology understands that discourse matters, but also resists thinking about urban landscapes and the bodies that inhabit them as derelict or in need of management through didactic lesson plans. The "purpose," or goal of urban ecologists is then to inquire with a "different science" (St. Pierre, 2010) that is emergent to the relations produced with and in environments. Ecologists therefore examine how urban places were used in the past (i.e., how place came to matter) and how such places can be re-thought and reengaged in un-coded ways that are intimately produced between inside-outside.

\section{Contingent Data}

Demanding a different science, St. Pierre re-enters fieldwork to collect more data through a nomadic writing practice. In search of the field, not knowing what or where that is, St. Pierre begins to question data (i.e., the capturable) and continues to question it (see St. Pierre, 2013). She asks: "How does theory influence what counts as data, i.e. what data become incoherent and what intelligible? What kind of knowledge is produced in this ricochet of theories" (2010, p. 378)? She anticipates that qualitative researchers will struggle in this theoretical-methodological space of entanglement, as I am admittedly grappling with questions that do not have a "general response." Within this text, I have been asking: How does movement move? And now I am thinking: What do the images captured by wearable technologies do?

Upon reading an interview that St. Pierre held with an 80 year-old woman who lived and re-lived years of loss, pain, and war, I, too, begin to wonder if our use of wearable technologies, the entanglement of posthumanist theories and new materialist methodologies, "or any other theory is any more useful than humanism when we are too close to the wrong side of that most material of binaries, life/death" (2010, p. 378). And like St. Pierre, I cannot help but still wonder, even at times when life feels unkind, uncaring, and unfair, what might become between life-death. What might qualitative practice do if researchers could rethink the visual image as that which outruns practice and undoes notions of subjectivity and existence as 'fixed?' How might qualitative researchers rethink data as contingent and process-orientated? I know that lingering in terminal scenarios will always result in what is promised to breathing bodies - more of the same. Qualitative researchers cannot just choose to freeze movement in time through the production of the visual image. Perhaps it is then between the ruderal cracks and zigzagging movements where the demands for a different science might 
actualize. Yet, to demand would be a humanist project, placing the "narrated body" at the centre of things (Manning, 2013a). Perhaps it is then an active curiosity of what might become of data inbetween its production and its replaying that does not demand difference, but could potentially reinvent a relay of data, a relay that doesn't loop around but rather creates anew, as Deleuze and Foucault had suggested. As Manning writes, "life is a complex of feeling, an ecology not reducible to its data, to its content or its from-takings" (2013a, p. 22). Science, social sciences, and other disciplines of study then might redraw different questions that know that matter matters and it moves. But also know that this knowing (i.e., the conscious subject) could never fully account for the more-than-human rhythms that form and inform place - a place which is simultaneously naturetechnology; male-female; black-white; local-global; present-past (Braidotti, 2013).

To think data as generative of what is yet-to-come opens up an ethico-political mode of engagement that works with the pain, the unkindness and unfairness in affirmative ways. Such an approach does not deny pain, nor horror; it re-works and re-values 'reality' so that healing and new modes of thought endure and sustain futurity (Braidotti, 2013). Thinking about data as part of a "natureculture continuum" (Braidotti, 2013) - which is not solely sustained by the human - requires a thinking of the visual images captured by wearable technologies as that which will continue to matter-matter differently in and of time. For instance, the re-valuation of data could involve the practice of replaying the video-image. This would not serve to witness what had happened; rather, in its replaying the image would come to matter-matter differently in and of (past-present-future) time, and in and of more-than-human environments. In the replaying of the image, researchers can therefore begin to - partially and contingently - map and create different nodes of movement. Mapping would not be undertaken as a process of application or evaluation, but rather "a co-causal thirdness of exploration that can be generative of new modes of practice and inquiry" (Manning \& Massumi, 214, p. 94). We (researcher, teachers, and students) can, for instance, map the movement of our running practice and the movements that led to the formation of the "Fun to Walk Club." As a technique, the mapping of movement thus points out the affects-effects of relations (i.e., how we moved and what running did). However, images as maps are partial and contingent things 'depending' on the relations they enter into and, of course, they always risk the construction of inhuman(e) cartographies - that is why the image must not reflect the past, but rather bear traces of what was, while it maps future coordinates in time.

Thinking data as that which is part of a continuum, suggests that what becomes capturable in time and as image-data could never be relived and certainly does not reflect what had happened. Time may have passed but its traces and its more-than-human relations are always moving, entering future connections and creating new cartographies that might offer "unheard of ideas and proposals" for thinking-practice (Guattari in Holmes, 2009). Thinking about data in this way is to rethink of it as a part of a continuum that does not invest in the dead-end economy of habitual practice. As part of a continuum, qualitative researchers can affirmatively grapple with the pain, loss, and horror of historical times, while simultaneously pushing beyond the limits of inhuman(e) cartographies, moving towards the production of an ethico-political landscape that informs itself. 


\section{Conclusion}

During his time as an experimental therapist in France, Guattari wondered if it was possible to conceive of a methodology that thinks practice (in his case, psychoanalysis) differently (Holmes, 2009). In this paper, I have attempted to rethink methodologies in educational research through a thinking-practice, which I have argued enables a thinking of method, methodologies, and data as that which matters-matters. And although I have offered a suggestion of how qualitative researchers might rethink data, this is by no means a formal call for a new method of application, nor is this a template for practice. Through the discussion presented, here, and through our use of wearable technologies in practices of group-running and in relation to learning, this paper attends to how movement moves. In doing so, movement was captured in the form of the visual image. In another attempt to undo traditional notions of the image/data as finite, I have suggested that the replaying of video can work to map the how of movement in order to disrupt representational practices that suggest that the image is a reflection of what had happened. Thinking of movement as that which never stops opens the qualitative field to a processual technique of mapping that creates future images of thought-practice (i.e., new nodes of research). This technique in turn requires an understanding that acknowledges that the uncapturable always exists and comes to matter in the formation of ecologies, as does the mapping process itself.

Lastly, entering a thinking-practice relation that is part of an embodied and embedded continuum, suggests that data must come to matter in ways that think beyond the limits of the body with organs. The body without organs, as Deleuze and Guattari (1987) write, has no expiration date, just networks, ebbs, flows, slowness, and speeds that simultaneously fall and rise in and of the morethan-human environments that it sustains and that sustain it. Methodology must then become an unsustainable process that sustains - through activation - new processes that will inevitably determine what has yet to materialize as existing, or 'real.' Sustaining the unsustainable thus puts in play an incessant questioning of thought and practice in an active attempt - never innocent - to keep moving towards and potentially beyond the limits of practice as qualitative researchers 'know' it.

\section{Acknowledgment:}

Thinking and writing at a time when life became unfair, I dedicate this essay in remembrance of our childhood friend, young mother, and inspiring woman who always wanted to do new things.

\section{References}

al-Rifaie, M., Bishop, M., \& Caines, S. (2012). Creativity and autonomy in swarm intelligence systems. Cognitive Computation, 4(3), 320-332. http://dx.doi.org/10.1007/s12559-012-9130-y

Barad, K. (2007). Meeting the Universe Halfway: Quantum Physics and the Entanglement of Matter and Meaning. Durham, NC: Duke University Press. http://dx.doi.org/10.1215/9780822388128

Bennett, J. (2010). Vibrant Matter. Durham, NC: Duke University Press.

Braidotti, R. (2013) The Posthuman. Cambridge, UK: Polity Press.

Braidotti, R. (2002). Metamorphoses. Cambridge, UK: Polity Press.

Britzman, D.P. (1998). Lost Subjects, Contested Objects: Toward a Psychoanalytic Inquiry of Learning. Albany: State University of New York Press.

DeLanda, M. (1995). Uniformity and variability: An essay in the philosophy of matter. Paper presented at the Doors of Perception 3 Conference, Netherlands Design Institute, Amsterdam, November 7-11. 
Deleuze, G. \& Guattari, F. (1987). A thousand plateaus: Capitalism and schizophrenia, trans. B.

Massumi. Minneapolis, MN: University of Minnesota Press.

Deleuze, G. \& Foucault, M. (1977). Intellectuals and power. In M. Foucault (Ed.). Language, Countermemory, Practice (pp. 205-206), trans. D. Bouchard and S. Simon. Ithaca, NY: Cornell University Press.

Deleuze, G., \& Guattari, F. (1977). Anti-Oedipus: Capitalism and Schizophrenia, trans. R. Hurley, M. Seem, and H. Lane. New York, NY: Penguin. de Freitas, E. (2014). Diagramming the classroom as a topological assemblage. In M. Carlin \& J. Wallin (Eds.). Deleuze \& Guattari, politics and education for a people yet-to-come (pp. 95-115). New York, NY: Bloomsbury.

Eisenman, P. (1999). Diagram diaries. New York, NY: Universe.

Gins, M. \& Arakawa, S. (2002). The architectural body. Tuscaloosa, AL: University of Alabama Press.

Gobster, P. (2012). Appreciating urban wildscapes: Towards a natural history of unnatural places. In A. Jorgensen \& R. Keenan (Eds.). Urban wildscapes (pp. 33-48). New York, NY: Routledge.

Grosz, E. (2011). Becoming Undone: Darwinian Reflections on Life, Politics, and Art.Durham, NC: Duke University Press.

Guattari, Felix. (2013). Schizoanalytic cartographies, trans. A. Goffey. New Delhi, IN: Bloomsbury.

Haraway, D. (2008). When species meet. Minneapolis, MN: University of Minnesota Press.

Haraway, D. (1991). Simians, cyborgs and women: The reinvention of nature. New York, NY: Routledge.

Hayles, K. (2012). How we think: Digital media and contemporary technogenesis. Chicago, IL: University of Chicago Press. http://dx.doi.org/10.7208/chicago/9780226321370.001.0001

Holmes, B. (2009). Guattari's Schizoanalytic Cartographies or, the pathic core at the heart of cybernetics. (http://brianholmes.wordpress.com/2009/02/27/guattaris-schizoanalyticcartographies/\#sdfootnote16sym). Accessed September 15, 2014.

Hultman, K. \& Lenz Taguchi, H (2010). Challenging anthropocentric analysis of visual data: A relational materialist methodological approach to educational research. International Journal of Qualitative Studies in Education, 23(5), 525-542. http://dx.doi.org/10.1080/09518398.2010.500628

James, W. (2003). Essays in radical empiricism. New York, NY: Dover.

Johnson, S. (2002). Emergence: The connected lives of ants, cities and software. New York, NY: Schribner. Jorgensen, A. \& Keenan, R. (Eds.). Urban wildscapes. New York, NY: Routledge.

Larsson, H. \& Quennerstedt, M. (2012). Understanding movement: A sociocultural approach to exploring moving humans. National Association for Kinesiology in Higher Education, 64, 283-298.

Manning, E. (2013a). Always more than one: Individuation's dance. Durham, NC: Duke University Press.

Manning, E. (2013b). Against method. Paper resented at the Ontario Institute for Studies in Education, University of Toronto, Toronto, Canada, November 21.

Manning, E., \& Massumi, B. (2014). Thought in the act: Passages in the ecology of experience. Minneapolis, MN: University of Minnesota Press.

Massumi, B. (2011). Semblance and Event: Activist Philosophy and the Occurrent Arts. Cambridge, MA: MIT Press.

Mazzei, L. (2010). "Thinking Data with Deleuze." International Journal of Qualitative Studies in Education 23(5), 511-523. http://dx.doi.org/10.1080/09518398.2010.497176

Mazzei, L. \& McCoy, K. (2010). Thinking with Deleuze in qualitative research. International Journal of Qualitative Studies in Education, 23(5), 503-509.

http://dx.doi.org/10.1080/09518398.2010.500634

McCready, L.T. \& Soloway, G.B. (2010). Teachers' perceptions of challenging student behaviours in model inner city schools. Emotional and Behavioural Difficulties, 15(2), 111-123.

http://dx.doi.org/10.1080/13632752.2010.480883

Phillips, D.K. \& Larson, M.L. (2012). The teacher-student writing conference entangled: Thinking data with material feminisms. Cultural Studies <-> Critical Methodologies, 12(3), 225-234. 
Rajchman, J. (1998). Constructions. Cambridge, MA: MIT Press.

Renold, E. \& Ivinson, G. (2013). Girls, camera, (intra)Action: Applying a diffractive analysis to teen girls' engagement with visual participatory methodologies. Paper presented at the American Educational Research Association Conference, San Francisco, California, April 28.

Rotas, N. (2012). Bodied curriculum: A rhizomean landscape of possibility. Master's Thesis, Ontario Institute for Studies in Education, University of Toronto, Ontario, Canada.

Sanders-Bustle, L. \& Oliver, K. (2001). The role of physical activity in the lives of researchers: A bodynarrative. Studies in Philosophy and Education, 20, 507-520. http://dx.doi.org/10.1023/A:1012282416927

Simondon, G. (1995). L'Individu et sa genese physio-biologique. Grenoble: Gerome Millon.

Snaza, N., Appelbaum, P., Bayne, S., Carlson, D., Morris, M., Rotas, N., Sandlin, J., Wallin, J., and Weaver, J. (forthcoming). Toward a Posthumanist Education. Journal of Curriculum Theorizing.

Springgay, S., \& Rotas, N. (2014). How do you make a classroom operate like a work of art? Deleuzeguattarian methodologies of research-creation. International Journal of Qualitative Studies in Education, 1-21. http://dx.doi.org/10.1080/09518398.2014.933913

St. Pierre, E.A. (2013). "The Posts Continue: Becoming." International Journal of Qualitative Studies in Education 26(6): 646-657. http://dx.doi.org/10.1080/09518398.2013.788754

St. Pierre, E.A. (2010). Methodology in the fold and the irruption of transgressive data. International Journal of Qualitative Studies in Education, 10(2), 175-189. http://dx.doi.org/10.1080/095183997237278

Tuck, E. (2013). Urban youth and school pushout: Gateways, get-aways, and the GED. New York, NY: Routledge.

Vehlken, S. (2013). Zootechnologies: Swarming as a cultural technique. Theory, Culture \& Society, 30(6), 110-131. http://dx.doi.org/10.1177/0263276413488959

Weaver, J. (2010). Educating the Posthuman. Rotterdam, NL: Sense Publishers. 